\title{
Establishment of System for Educating and Cultivating Excellent Engineers through School- enterprise Cooperation
}

\author{
LIANG Yuehua \\ School of Civil Engineering and Architecture \\ Panzhihua University \\ Panzhihua, Sichuan, China \\ 380281015@qq.com \\ SUN Jinkun \\ School of Civil Engineering and Architecture \\ Panzhihua University \\ Panzhihua, Sichuan, China
}

\author{
WANG Jie \\ School of Civil Engineering and Architecture \\ Panzhihua University \\ Panzhihua, Sichuan, China \\ LI Xiaoming \\ School of Civil Engineering and Architecture \\ Panzhihua University \\ Panzhihua, Sichuan, China
}

\begin{abstract}
This paper takes "A Plan for Educating and Cultivating Excellent Engineers" majored in civil engineering based on school-enterprise cooperation in Panzhihua University as an example. A set of system is constructed for the cocultivating excellent engineering through a kind of suitable school-enterprise cooperation, as shown that: organizational setting, teaching operation and management, cultivating objectives and plans, curriculum system setting, teaching methods, contents reform, teaching staff construction, and ways of school-enterprises, which provide ideas and references for cultivating excellent engineers majored in civil engineering in ordinary local colleges and universities.
\end{abstract}

Keywords-School-enterprise cooperation; Excellent engineer; Civil engineering

\section{INTRODUCTION}

Since June 2010 the Ministry of Education implemented Outline of National Medium- and Long-term Program for Education Reform and Development (2010-2020) and Outline of National Medium- and Long-term Program for Talent Development (2010-2020) and launched "A Plan for Educating and Training Excellent Engineers"[1],[2] (Hereafter referred to as "Excellence Plan"), colleges and universities actively declare, participate, explore and practice. Civil engineering major of Panzhihua University is listed as the first batch of disciplines of "the Plan for Training Excellent Engineers" in Sichuan Province in 2012[3]. Combining with talents training ideas of "rooting in the fertile soil in the region of Panzhihua and Xichang, serving resource development, adhering to the combination of production, education and research, and training applied talents"[4], the university, for "the Plan for Training Excellent Engineers" in civil engineering, draws on the successful experience of engineering education at home and abroad, and establishes "engineering-oriented, productionoriented, future-oriented" engineering education concepts. Oriented to social demand, and taking engineering practice as the background and engineering technology as the main line, we should focus on improving students' engineering awareness, engineering quality and ability of engineering practice, and pay more attention to cultivate students' innovation, creativity, and entrepreneurial ability.

Engineering practice is the core of the "Excellence Plan". Combining with the specialized characteristics of civil engineering, and taking the "Excellence Plan" in civil engineering major of Panzhihua University as an example, this paper discusses the school-enterprise cooperation of the excellent engineers in civil engineering, and the establishment of cooperative system and mechanism, as well as the cultivation pattern of collaborative teaching, which provide ideas for the training of engineering engineers majored in engineering in local colleges and universities.

\section{ORGANIZATIONAL GUARANTEE}

For the smooth implementation of policies and the smooth progress of cultivation of "excellent engineers", strong organizational guarantee measures must be made.

\section{A. Organizational framework}

To "the Plan for Educating and Cultivating Excellent Engineers", two-levels of organization and management system of college's centralized guidance and college's specific implementation are used in our university.

The college sets up the "Leading Group of the Plan for Cultivating Excellent Engineers". Based on the characteristics of discipline areas of civil engineering major and the specific situation of the college, the college sets up the college-level leading group for enterprise cooperation and participation to take charge of the specific construction work of the "Excellence Plan". 


\section{B. Teaching operation and management}

The school is responsible for the validation of the training scheme of "Excellence Plan" and its implementation and inspection. The college establishes the expert group above Deputy High class (more than 2/3 of "dual qualified" experts with the engineering background) to be responsible for specific implementation. Related leaders and supervisors of the college's Dean' Office participates.

Also, the college should organize the teaching operation and management in discipline areas of "Excellence Plan". The college-level leading group specifically coordinates and implements the construction work.

\section{CULTIVATION PATTERN EXPLORATION}

\section{A. Cultivation standards and plans}

Cultivation standards of the civil engineering should be established based on the common standard, the industry standard, and the requirements of the majors. According to the standard of cultivation and specialized characteristics of civil engineering, the cultivation plans could be established.

Guiding thoughts are as follows:

1) Emphasizing multidisciplinary support. In accordance with the oriented ideas of industrial needs, students must integrate the basic knowledge of the relevant disciplines and basic skills. On this account, cultivation standards and plans focus on multidisciplinary support and complementarity.

2) Strengthening engineering practice ability. Engineering practice is core of the "Excellence Plan". Based on the characteristics of each major, the cultivation of engineering practice ability is gradually and hierarchically refined to every link in many ways of strengthening, inside and outside of the class, internal and external of the school.

3) Highlighting the internationalization and frontier of engineering education. Internationalization and frontier are the general trends of engineering education, which requires the major of "Excellence Plan" to take "Large-scale Engineering" as the perspective to build a modern engineer's knowledge structure and capacity quality, understand the most recent industrial technology, introduce technical standards and industry norms, expand the international vision, and cultivate high-level talents.

4) Emphasizing social responsibility. The professional activities of the engineers have a direct impact on the society and the society more and more demands the professional quality, the occupational ethics and the personality quality of the engineers themselves.

\section{B. Curriculum system and teaching contents reform}

1) Setting thoughts and principles of curriculum system. Setting the curriculum system should consider both the discipline properties and industry background. Neither ignores the basis of discipline for emphasizing industry standards, nor weakens the industry characteristics for stressing disciplinary basis. In accordance with the general framework of "general education courses, basic courses of general disciplines, specialized courses (major basic courses, major direction courses, major front course)", the curriculum system is built.

2) Implementation situation and typical measures of teaching content reform.

In view of the characteristics of "Excellence Plan", the focuses of teaching contents reform are approaching to engineering reality, strengthening engineering practice, cultivating engineering quality, and improving practical innovation ability.

According to technical updates and changes in the academic field in recent years, teaching plan should be rerevised. Technical documents of main engineering standards and norms involved in specialized courses is found out and by comparing and combing the course knowledge points, the work of complement, deletion, and update are done. Then in the form of questionnaire survey and meeting discussion to take advice of joint training enterprises and the relevant member units of provincial and municipal architecture academies, ultimately a new teaching plan of specialized curriculum is formed.

The curriculum system and contents are constantly adjusted to form the flexible curriculum system and dynamic teaching plan that coincide with national norms and are oriented to enterprise needs. Mostly, the practical teaching links of experiment and training should be planned, and the gradient practice teaching system with the main line of the "introduction of industry $\rightarrow$ recognition of the internship $\rightarrow$ curriculum of the internship $\rightarrow$ production internship $\rightarrow$ graduation internship $\rightarrow$ enterprise internship" is implemented.

\section{Teaching methods reform}

1) Integrating major to teach basic theoretical knowledge. At the beginning of the class of basic theory courses, students know little about the professional knowledge, so they do not understand the role of basic theory courses played in the major. With the purpose of improving students' study of the basic courses, the teachers teaching basic theory courses are required to explain the basic theory courses in combination with professional examples. This not only increases the course challenge, but also raises a higher demand for teachers.

2) Integrating scientific research, and engineering practice to teach professional courses. To teach all the professional courses and module courses in professional direction offered, teachers adopt the teaching methods combined with scientific research and engineering practice and pass on new ideas, new technologies, and application situations to the students.

3) Teaching methods of school-enterprise cooperation. Hire senior engineer (national registered engineer) and experts above the senior engineer title to teach part of the contents of some corresponding core curriculum. For example, a series of school-enterprise cooperation courses are set up according to the following patterns: Experts above Deputy High class in designing colleges teach CAD Drawing, Structure Design; Directors of supervision units (registered supervision engineer) teach Construction Project Management; Registered cost 
engineers in Budget Consulting Organizations teach Project Budget; Project managers and chief technical engineers in construction enterprises teach respectively Project Management and Construction Technology.

4) On-the-spot teaching. For students to better understand, courses with strong practicality are taught by on-the-spot teaching methods.

5) Strengthening the virtual simulation practice teaching. The construction of the virtual simulation practice teaching center should be strengthened, and a new practical teaching platform is built for students to let students learn professional knowledge in the "game".

6) Promoting the "project-driven" case-based teaching methods. The core idea of "project-driven" case-based teaching method is to take the project practice as the main line and to promote the study of theoretical knowledge by practice so as to improve the initiative and purpose of learning. In the process of teaching, teachers mainly guide and inspire the students, and at the same time focus on the carding and induction of theoretical knowledge.

7) Establishing ability for optimal evaluation way. The evaluation of student's practice scores is different from the traditional practice assessment method, for it focusing more on the assessment of students' practical ability, comprehensive applying ability, document writing ability, teamwork collaboration and innovation ability. Through constructing different evaluation indicators, students' performance is evaluated comprehensively.

8) Expanding students' learning horizons in multiple ways. Through organizing students to participate in important domestic and international competitions in the disciplines fields, adding practice and field research subjects, inviting senior engineers in enterprises to give academic lectures, and carrying out a variety of joint teaching patterns, students' learning horizons are expanded.

\section{TEACHING STAFF CONSTRUCTION}

Only excellent teachers can cultivate outstanding talents, so the school takes a lot of measures to strengthen the teaching staff construction of "Excellent Plan"[5]. And "Double Enter" work that the college teachers enter the enterprises and engineers above senior class in enterprises enter the classroom is actively carried out to achieve on the seamless docking between the school and enterprises in personnel training and scientific and technical services [4].

\section{A. Strengthening the background training of teaching staff .}

The intensity of school-enterprise cooperation should be increased to build a platform for teachers to enhance practical ability and to get training and growth in practice, thus creating high-level dual qualified teaching talents in engineering and technology. The relevant system of teachers post practice is improved, and teachers are encouraged to be tempered through titular position in the government departments, enterprises and institutions to get the industry background training, all of which are given policy support; Professional and technical teachers are encouraged to do part-time jobs and get remuneration in the counterparts unites or create scientific and technological innovation enterprises to transform scientific and technological achievements, which can promote teachers to go deep into the production line to more directly understand the industry trends and enterprise needs, accumulate engineering experience, and improve teachers practical teaching ability; Teachers are encouraged to obtain various registered certificates in the industry (such as registered architects, registered constructor, registered supervision engineers, etc.), and the teachers title assessment of engineering sequence is further opened to expand the team size of "dual qualified" teachers; With the policy support, the college stipulates that all young teachers must have the experience of industry work or training, which provides strong teachers' support for cultivating applied talents with innovative and entrepreneurial ability [6].

\section{B. Hiring senior professionals in the industry to teach.}

Colleges and enterprises should select and identify together some experienced, responsible, professional and technical persons with or above a bachelor's degree and above Deputy High title in the engineering education centers (bases) and cooperative enterprises as part-time teachers of enterprises to directly teach students, direct the practice, practice or give academic lectures, guide the curriculum settings, and revise the cultivation plan. For part-time teachers of enterprises, the appointment system is implemented, implementing annual appraisal within the appointment period.

\section{Sharing talents resources between colleges and enterprises}

Strengthening the school-enterprise cooperation and jointly constructing the teaching staff can train the teachers and make them grow in the production, which can help the teachers know the development status of the industry and grasp the most cutting-edge engineering technology, while providing strong theoretical support for enterprises; Enterprises' senior technical personnel entering the college can make the enterprises better understand the college's resources and advantages, strengthen their own basic theoretical level and and improve scientific research and innovation ability[7].

\section{SCHOOL-ENTERPRISE COOPERATION PLATFORM CONSTRUCTION}

As for the cooperation pattern, while the traditional pattern of cooperation is retained, through innovation, new schoolenterprise cooperation model of high level engineering education that is suitable for the college situations and has the characteristics of the era is explored.

Internship (practice) bases construction. Through the levels of college and college, cooperation agreements were signed and practical and education bases were established with more than 20 large- and medium-sized enterprises and scientific research colleges, including Panzhihua Iron \& Steel (Group) Company, Panzhihua Coal (Group) Ltd. Company, Panzhihua Iron and Steel Research College, Panzhihua Iron and Steel Engineering Technology Co., Ltd., Southwest Geo-technical Investigation Design College of Nuclear Industry, China $19^{\text {th }}$ 
Metallurgical Corporation and so on. Taking the following aspects: construction of discipline and profession and scientific research, teachers training, building joint experimental and scientific research platform together, and carrying out joint scientific research to tackle the key research projects and collaborative innovation as the carriers, the school-enterprise industry alliance is established to promote the transformation of results. "Sichuan Province Key Laboratory of Higher Education Institutions for Comprehensive Development and Utilization of Industrial Solid Waste in Civil Engineering" is co-constructed with Architectural Design and Research College of China $19^{\text {th }}$ Metallurgical Corporation, Panzhihua Iron and Steel Engineering Technology Co., Ltd., and China Southwest Geo-technical Investigation Design College. The college and Sichuan Zhongyu Construction Engineering Co., Ltd. jointly set up Sichuan Huayue Engineering Detection Co., Ltd., to provide platform for teachers and students to learn and understand the nondestructive testing.

In accordance with the depth of cooperation and specifications, the cooperative enterprises will be divided into different types to carry out different levels of cooperation. The enterprises specifically include: 1) Listed enterprises are the deeply strategic and cooperative enterprises. Both the college and enterprises undertake the students' cultivation and scientific research tasks. Cooperation agreements are signed in line with the school-level specifications, and the enterprises list the "Cooperation Unit of the Plan for Excellence Engineer of Panzhihua University ". 2) Enterprises in-kind agreement is the key cooperative enterprises. Both the college and enterprises undertake the task of cultivating students. Cooperation agreements are signed in line with the school-level specifications, and the enterprises list the "Assisting Unit of the Plan for Excellence Engineer of College of Civil Engineering and Architecture of Panzhihua University". 3) Participating enterprises are the key participating enterprises, which provide students with internships and undertake cognitive tasks. Cooperation agreements are signed in line with the school-level specifications. Enterprises are not listed.

\section{CONCLUSION}

The "Plan for Educating and Cultivating Excellent Engineer" is a major research subject of high level engineering education in China. It is an important element of applied transformation for colleges and universities. Its core is to cultivate compound and applied talents with advanced technology. How to mobilize all forces and combine with the college's and professional characteristics to construct the system for cultivating excellent engineer and to educate and cultivate excellent talents is an arduous and important task which needs long-term and extensive research and practice [11].

\section{REFERENCES}

[1] The State Council. "Outline of National Medium- and Long-term Program for Education Reform and Development (2010-2020)”, 2010 (In Chinese).

[2] The State Council. "Outline of National Medium- and Long-term Program for Talent Development(2010-2020)”, 2010 (In Chinese).

[3] X. Xiaoqian, W. Jie, C. Kecai, "Discussion on the Plan for Cultivating Excellent Engineer", Journal of Sichuan University of Technology, no. 6, 2015 (In Chinese).

[4] H. Shuanghua, "Highlighting Characteristics to Enhance Local Universities Service Capacity for Society", China Higher Education, no. 21, pp. 39-41, 2011 (In Chinese).

[5] H. Shuanghua, "A Study on the Construction of Teacher Team in Local High-level Characteristic University (upper part)", Journal of Panzhihua University, no. 4, pp. 62-63, 2013 (In Chinese).

[6] H. Shuanghua, "A Study on the Construction of Teacher Team in Local High-level Characteristic University (lower part)", Journal of Panzhihua University, no. 5, pp. 67-70, 2013 (In Chinese).

[7] L. Zilin, "The Training and Research of the Excellent Engineers in the Civil Engineering", Journal of Tianjin College of Urban Construction, vol. 30, no. 1, pp. 72-76, 2013 (In Chinese).

[8] S. Li, L. Yongcheng, C. Lv, "Building of Applied Innovative Talents Training System in Local Colleges", Research and Exploration in Laboratory, vol. 30, no. 1, pp.143-145, 2011(In Chinese).

[9] W. Changheng, "Study on the Training and Educating System Construction of the New Ecology for Innovation and Entrepreneurship Education in Universities", Continue Education Research, no. 2, pp. 4243, 2012 (In Chinese).

[10] W. Changheng, "Research on Pattern and Mechanism of Training Excellent Engineers by School-enterprise Cooperation", Education and Vocation, no. 30, pp. 14-17, 2010 (In Chinese).

[11] L. Dong, "Research on Pattern of Cultivating Excellent Engineers in Architecture and Environment by Coalition of Colleges and Enterprises", Journal of Higher Education of Southwest University of Science and Technology, no. 2, pp. 45-47, 2015 (In Chinese). 